\title{
Predicting the Thickness of the Hardening Coating during Diffusion Metallization of Cast Iron
}

\author{
Alexander Veselovsky ${ }^{1, a}$, Irina Troyanovskaya ${ }^{2, b^{*}}$ and Valery Erofeev ${ }^{2, c}$ \\ ${ }^{1}$ Production Company "Travel Systems", 52 Karl Marx Street, Chelyabinsk, Russia \\ 2 South Ural State Agrarian University, 75 Lenin Avenue, Chelyabinsk, Russia \\ aa_a_ves@mail.ru, btripav63@mail.ru, cervv52@mail.ru
}

Keywords: Diffusion, Coating, Saturation, Cast Iron, Carbides

\begin{abstract}
The article presents the calculations of diffusion indices of saturation of high-strength cast iron VCh 60 from powder filling. Carbide-forming elements were used as diffusers: vanadium, chromium and manganese. As a result of the research, empirical equations have been established for predicting the thickness of strengthening diffusion coatings depending on the temperature and saturation time.
\end{abstract}

\section{Introduction}

Methods of chemical-thermal treatment are the most promising methods for hardening the surface of products made of high-strength cast iron. Methods of diffusion metallization are widely used among them $[1,2,3,4]$. Diffusion metallization restores parts with low wear, high surface hardness and working under conditions of friction with a variety of mating materials [5]. The diffusion metallization process is most widely used for parts of diesel fuel equipment. It is used for parts with fixed joint seating surfaces and which are characterized by low wear. For example, shafts, bearing cups of gearboxes, rear axles, gearboxes and others. Diffusion metallization is also used in movable joints, such as rocker shafts, idler shafts, water and oil pump shafts, and others.

Diffusion metallization repairs cast iron parts with wear within the coating thickness using pastes and coatings [6,7]. Their composition is identical to the powder reaction mixture containing diffusing components.

\section{Materials and methods}

For the thermal diffusion hardening of specimens of high-strength cast iron VCh 60 , the following components were taken from the powder medium $[8,9]$ :

1. Ferrovanadium with a vanadium content of at least $50 \%$ by weight;

2. Ferromanganese with an average manganese content of $88 \%$ by weight;

3. High-carbon ferrochrome with a chromium content of more than $65 \%$, carbon, respectively $8-8.5 \%$ and silicon not more than $2 \%$;

4. Aluminum oxide;

5. Ammonium chloride.

These ferroalloys are widely used in the metallurgical industry for alloying cast iron [10, 11, 12]. Ammonium chloride is an activator. It has a low temperature of thermal dissociation $\left(350^{\circ} \mathrm{C}\right)$, as a result of which ammonia and hydrogen chloride are formed. Hydrogen chloride reacts with the main diffusers in the charge to form chlorides and subchlorides, which are directly involved in diffusion saturation. Ammonia thermodissociates with the formation of hydrogen and nitrogen at temperatures of $450-500{ }^{\circ} \mathrm{C}$. Aluminum oxide is highly refractory and inert to most reagents in direct contact with it at high temperatures. Therefore, it is used as an inert filler. 
The preparation of charge materials was carried out in the following sequence. Crushed into powder ferroalloys were sieved through a sieve with a mesh size of $1 \mathrm{~mm}$. In the beginning, all the components used were heated. Aluminum oxide was heated for one hour at a temperature of 700 ${ }^{0} \mathrm{C}$. Ammonium chloride was heated for 2 hours at a temperature of $200{ }^{0} \mathrm{C}$.

The initial components of the mixture were weighed with an accuracy of $0.5 \%$, mixed until homogeneous and poured into an airtight container before use. Thermal diffusion saturation was carried out in a muffle furnace using a container with a fusible seal. Samples of high-strength cast iron VCh 60 were placed in a furnace and covered with a powder reaction mixture. Then the container was packed. The saturation temperature was $1020-1050{ }^{0} \mathrm{C}$. The saturation time was 56 hours for vanadium coatings and 10-12 hours for chrome and manganese coatings.

Changes in the overall dimensions of the samples were carried out using a scanning electron microscope after chemical thermal treatment [13].

\section{Results and discussion}

Based on the first law of diffusion, the thickness of the diffusion layer $\delta$ at a constant saturation concentration is

$$
\delta=K \sqrt{D \tau},
$$

where $K$ is coefficient depending on the type and conditions of saturation; $D$ is diffusion coefficient; $\tau$ is saturation time.

Taking into account the temperature dependence of the diffusion coefficient $D$, we have

$$
\delta^{2}=K^{2} \tau D_{0} e^{-E / R T},
$$

where $E$ is diffusion activation energy; $R$ is gas constant; $T$ is absolute temperature; $D_{0}$ is preexponential factor.

At a constant temperature $T=$ const, the thickness of the diffusion coating $\delta$ depends only on the time of the saturation process $\tau$. We introduced the designation $2 p=K^{2} D_{0} e^{-E / R T}$ and received $\delta^{2}=2 p \tau$.

We have built graphical dependences $\delta^{2}=f(\tau)$ of the thickness of the diffusion layer on the saturation time (Figure 1). Then the quantity $2 p$ is the tangent of the slope of the straight lines. The calculation results are presented in Table 1.

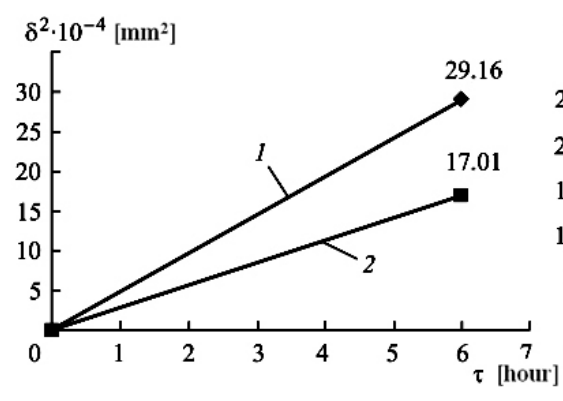

a)

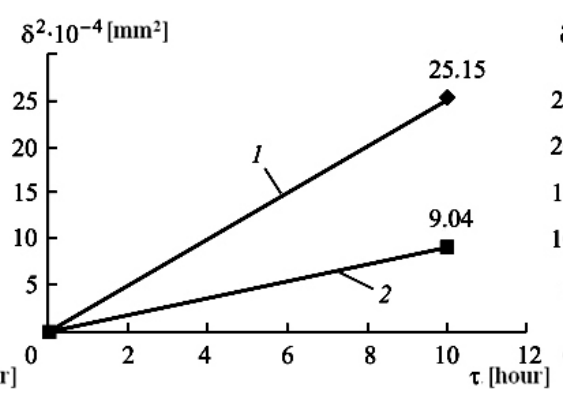

b)

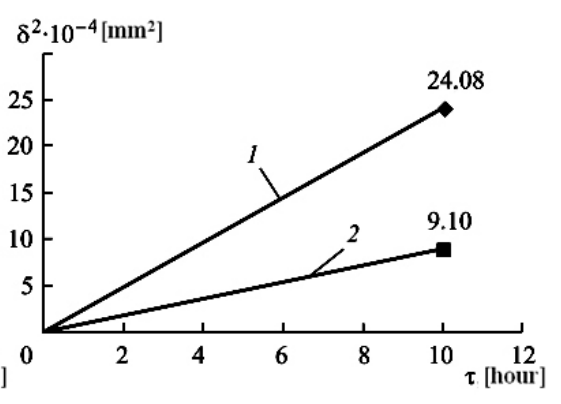

c)

Fig. 1. Dependence $\delta^{2}$ on the saturation time $\tau$ of VCh 60 cast iron (a) with vanadium, (b) chromium (c), manganese at a temperature of (1) $1050{ }^{\circ} \mathrm{C}$ and (2) $960{ }^{\circ} \mathrm{C}$ 
Table 1. Calculation results $2 p$

\begin{tabular}{|c|c|c|c|c|}
\hline \multirow{2}{*}{ Diffusing element } & Temperature $\left[{ }^{0} \mathrm{C}\right] /[\mathrm{K}]$ & $1 / T \cdot 10^{-3}$ & $2 p \cdot 10^{-4}$ & $\ln (2 p)$ \\
\hline \multirow{2}{*}{ Vanadium } & $960 / 1233$ & 0.811 & 2.90 & -8.14 \\
& $1050 / 1323$ & 0.756 & 4.86 & -7.63 \\
\hline \multirow{2}{*}{ Chromium } & $960 / 1233$ & 0.811 & 1.02 & -9.19 \\
& $1050 / 1323$ & 0.756 & 2.51 & $-8,29$ \\
\hline \multirow{2}{*}{ Manganese } & $960 / 1233$ & 0.811 & 0.94 & -9.32 \\
& $1050 / 1323$ & 0.756 & 2.46 & -8.33 \\
\hline
\end{tabular}

After taking the logarithm, we got

$\ln (2 p)=\ln \left(K^{2} D_{0}\right)-E / R T$

At $T=\infty$ or $1 / T=0$ equation (3) takes the form

$\ln (2 p)=\ln \left(K^{2} D_{0}\right)$

We have built a graph $\ln (2 p)=f(1 / T)$ (Figure 2$)$.

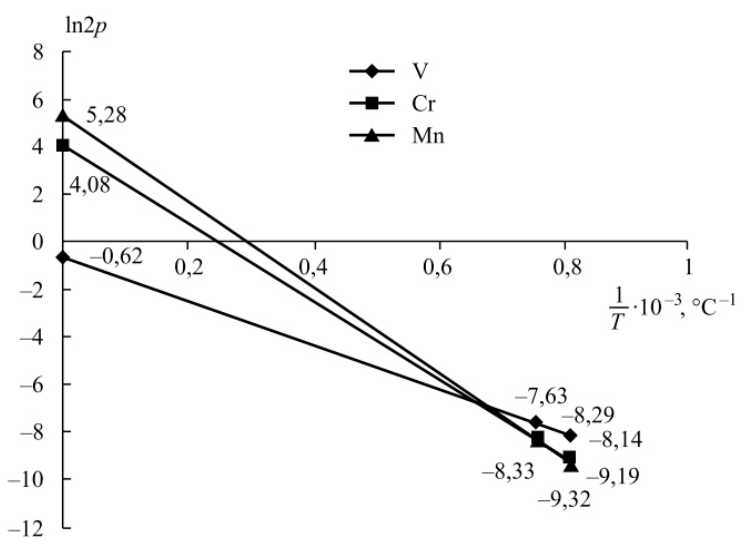

Fig. 2. Dependence $\ln (2 p)=f(1 / T)$

The coordinates of the points of intersection of straight lines with the $\ln (2 p)$ axis are obtained on the basis of the equation of a straight line passing through two points with known coordinates

$$
\frac{\left(x-x_{1}\right)}{\left(x_{2}-x_{1}\right)}=\frac{\left(y-y_{1}\right)}{\left(y_{2}-y_{1}\right)}
$$

Equation (3) implied

$$
\ln \left(K^{2} D_{0}\right)-\ln (2 p)=E / R T
$$

From Figure 2, taking into account $\ln (2 p)=f(1 / T)$ was follows $\operatorname{tg} \alpha=\frac{E}{R T} / \frac{1}{T}=\frac{E}{R}$. Then we got

$$
E=\operatorname{Rtg} \alpha
$$


Substitute equation (7) into equation (8) and obtain

$$
\operatorname{tg} \alpha=\left(\ln K^{2} D_{0}-\ln 2 p\right) T .
$$

The found values of $\ln \left(K^{2} D_{0}\right)$ and $\ln (2 p)$ were substituted into equation (9) and found the values of $\operatorname{tg} \alpha$ and $E$ for the corresponding temperatures (Table 2).

Table 2. Calculation results of $\operatorname{tg} \alpha$ and $E$

\begin{tabular}{|c|c|c|c|c|}
\hline Saturated element & Equation of a straight line & $\ln \left(K^{2} D_{0}\right)$ & $\operatorname{tg} \alpha$ & $E[\mathrm{~J} / \mathrm{mol}]$ \\
\hline Vanadium & $y=-9.27 \cdot 10^{3} \mathrm{x}-0.62$ & -0.62 & 9274.23 & 77106 \\
\hline Chromium & $y=-16.36 \cdot 10^{3} \mathrm{x}+4.08$ & 4.08 & 16365.5 & 136059 \\
\hline Manganese & $y=-18 \cdot 10^{3} \mathrm{x}+5.28$ & 5.28 & 18006.1 & 149702 \\
\hline
\end{tabular}

The calculated values of the activation energy of diffusion $E$ made it possible to obtain an empirical formula for the dependence of the thickness of the diffusion layer $\delta$ on the temperature $T$ and the time of diffusion saturation $\tau$.

To determine the unknown values of $K^{2} D_{0}$, experimental values of $\delta(\mu \mathrm{m})$ were substituted into formulas (2) at the corresponding values of temperature $T[\mathrm{~K}]$ and time $\tau$ [sec]

$\delta^{2}=192.3 \tau e^{-9274 / T}$ is empirical equation for vanadium coating;

$\delta^{2}=20161.0 \tau e^{-16365 / T}$ is empirical equation for chrome plating;

$\delta^{2}=73529.1 \tau e^{-18006 / T}$ is empirical equation for manganese coatings.

Thermal diffusion saturation of iron-carbon alloys with carbide-forming elements is characterized by an increase in the linear dimensions of products due to carbide formation. The increment of linear dimensions in cast iron is close to the thickness of the formed carbide layer.

Only a slight diffusion of vanadium, chromium and manganese into cast iron is possible at the initial moment of saturation, when the concentration of diffusant condensed on the surface to be hardened has not reached the stoichiometric value for the formation of carbides. However, the concentration of the strengthening components is low. In the vanadium process of gray cast iron, the concentration of vanadium diffusing deep into the part at the boundary with the cast iron base does not exceed $10 \%$ by weight. After reaching the stoichiometry of carbide formation, the diffusion mobility of vanadium, chromium, and manganese atoms is lost and the diffusion front shifts towards an increase in the size of the part, since the settling diffusant is bound into carbides due to the diffusion of carbon from the central layers. The counter diffusion of carbon significantly exceeds the diffusion fluxes of vanadium, chromium, and manganese. Therefore, the study of the kinetics of thermal diffusion vanadium, chromium plating, and manganization must be estimated from the diffusion mobility of the counter flow of carbon through the created carbide layer to the diffusion (reaction) front.

\section{Conclusion}

The obtained empirical regularities of the thickness of diffusion vanadium, chromium and manganese coatings make it possible to predict the thickness of the created diffusion layers under given saturation conditions and using the appropriate type and concentration of reagents according to the known control parameters - saturation temperature and time. 


\section{References}

[1] E.E. Bobylyov, I.D. Storozhenko, Diffusion metallization of carbide cutting tools as a way to improve the surface treatment quality, Journal of Physics: Conference Series. 1399(4) (2019) 044084. https://doi.org/10.1088/1742-6596/1399/4/044084

[2] P.O. Rusinov, Z.M. Blednova, Formation of the surface layers of a material with shapememory-based tinico diffusion metallization, Materials Science Forum. 818 (2015) 3-6. https://doi.org/10.4028/www.scientific.net/MSF.818.3

[3] Y.V. Zaulychny, V.G. Hignjak, N.A. Harchenko, T.P. Hovorun, O.V. Hignjak, V.Y. Dolgikh, Influence of interatomic interaction processes on the mechanical properties of carbide coatings based on $\mathrm{Ti}, \mathrm{V}$ and $\mathrm{Cr}$, obtained by diffusion metallization, Journal of Nano- and Electronic Physics. 8(4) (2016) 04008. https://doi.org/10.21272/jnep.8(4(1)).04008

[4] A. Pastukhov, O. Sharaya, E. Timashov, D. Bakharev, Method of justification of machine parts hardening modes, Engineering for Rural Development. 20 (2021) 74-79. https://doi.org/10.22616/ERDev.2021.20.TF016

[5] X-J. Liu, H-C. Wang Microstructure and hardness of vanadium carbide coatings prepared by thermal diffusion process on different steel substrate, Cailiao Rechuli Xuebao/Transactions of Materials and Heat Treatment. 31(1) (2010) 150-154

[6] A.A. Veselovskii, Improving the wear resistance of high-strength cast-iron gears by applying a thermodiffusional vanadium coating, Russian Engineering Research. 32(1) (2012) 4547 https://doi.org/10.3103/S1068798X12010273

[7] O.J. Akinribide, S.O. Olusunle, S.O. Akinwamide, B.J. Babalola, P.A. Olubambi, Impact of heat treatment on mechanical and tribological behaviour of unalloyed and alloyed ductile iron, Journal of Materials Research and Technology. 14 (2021) 1809-1819 https://doi.org/10.1016/j.jmrt.2021.07.077

[8] B. Wang, F. Qiu, G.C. Barber, Y. Pan, W. Cui, R. Wang, Microstructure, wear behavior and surface hardening of austempered ductile iron, Journal of Materials, Research and Technology. 9(5) (2020) 9838-9855. https://doi.org/10.1016/j.jmrt.2020.06.076

[9] A.A. Veselovsky, R.R. Dema, O.B. Kalugina, S.P. Nefedyev, Determination of parts tolerances in friction knots of grey and nodular cast iron with thermal diffusion platings vanadium and chrome, MATEC Web of Conferences. 129 (2017) 02043.

doi:10.1051/matecconf/201712902043

[10] A.I. Degula, T.P. Govorun, N.A. Kharchenko, V.G. Khyzhnyak, M.V. Karpets, O.M. Myslyvchenko, R.S. Smetanin, Investigation of the phase and chemical compositions of complex carbide coatings. Metallofizika i Noveishie Tekhnologii. 37(11) (2016) 1461-1476.

https://doi.org/10.15407/mfint.37.11.1461

[11] O.I. Shinskij, V.I. Litovka, V.A. Maslyuk, V.Ya. Kurovskij, N.V. Borovik, Production of high-strength cast iron with the use of briquetted modifiers, Litejnoe Proizvodstvo. 8 (2003) 2326.

[12] V.G. Hignjak, G.Y. Calashnicov, N.A. Harchenko, T.P. Hovorun, O.V. Hignjak, V.Y. Dolgikh, O.O. Holyshevskiy, The structure, composition and properties of nitrided alloys after diffusion metallization, Journal of Nano- and Electronic Physics. 7(4) (2015) 04033.

[13] A.A. Veselovsky, R.R. Dema, O.B. Kalugina, S.P. Nefedyev, Determination of parts tolerances in friction knots of grey and nodular cast iron with thermal diffusion platings vanadium and chrome, MATEC Web of Conferences 129 (2017) 02043

https://doi.org/10.1051/matecconf/201712902043 